\title{
Knowledge and practice of menstrual hygiene management among women living in a low-income neighbourhood, Karachi, Pakistan
}

\author{
Ghazala Usman', Kiran Abbas²*, Rimsha Arshad², Amna Muneer ${ }^{3}$, Hiba S. Syed ${ }^{3}$, \\ Anoosha Iqbal' ${ }^{2}$, Farea N. Dar², Urfa Anum², Moiz Ahmed², Khudija Tehreem¹, \\ Muhammad Hassan Zulfi ${ }^{1}$, Javeria Khan ${ }^{1}$
}

\begin{abstract}
${ }^{1}$ Department of Community Medicine, Jinnah Sindh Medical University, Karachi, Pakistan
${ }^{2}$ Department of Medicine, Jinnah Postgraduate Medical Centre, Karachi, Pakistan

${ }^{3}$ Department of Medicine, Aga Khan University Hospital, Karachi, Pakistan
\end{abstract}

Received: 11 July 2020

Revised: 19 August 2020

Accepted: 03 September 2020

\author{
*Correspondence: \\ Dr. Kiran Abbas, \\ E-mail: kiranabbas2020@gmail.com
}

Copyright: (c) the author(s), publisher and licensee Medip Academy. This is an open-access article distributed under the terms of the Creative Commons Attribution Non-Commercial License, which permits unrestricted non-commercial use, distribution, and reproduction in any medium, provided the original work is properly cited.

\begin{abstract}
Background: The aim of the study was to determine the degree of awareness and practice of proper menstrual hygiene management among women living in low-income neighbourhood in Karachi, Pakistan.

Methods: A cross-sectional study was conducted at the Bizerta Lines, Karachi between January and June 2019. All women of reproductive age were included in the study. Amenorrheic, menopausal, or women on birth control were excluded from the study. Degree of awareness and current practices pertaining to menstrual hygiene management were assessed through pro-forma. The study tool collected the participant's knowledge, awareness, and misconceptions about menstruation. The factors affecting the quality of life during menstruation of women living in poor socio-economic conditions were also observed. Statistical Package for Social Sciences (SPSS v.23) was used to analyze the collected data.

Results: Of the 338 participants, $82.5 \%$ had no knowledge of menstruation prior to their first menstrual period. Only a minority of the women knew that the source of menstrual blood was the uterus while $41.4 \%$ of the women incorrectly claimed that the menstrual blood and urine were expelled from the same orifice. More than half of the participants used disposable sanitary napkins (55.5\%). 65\% of the participants changed the absorbent at least 1 to 3 times a day.

Conclusions: Most of the participants used disposable sanitary napkins. However, the basic knowledge of female anatomy and physiology behind menstruation was poor among women.
\end{abstract}

Keywords: Adolescent, Culture, Health, Infections, Menstruation, Menarche, Menstrual hygiene, Reproductive Health, Taboos, Water supply and sanitation

\section{INTRODUCTION}

Menstruation is the monthly shedding of the endometrial lining of the uterus. It is a natural physiological process experienced by all women of reproductive age. ${ }^{1}$ Globally women constitute $49.6 \%$ of the population. ${ }^{2}$ The average woman menstruates from the age of 13 years to 51 years. ${ }^{3}$ Almost 6.25 years of a woman is spent menstruating.
Despite that knowledge regarding menstruation is low and taboos about menstrual periods are very common in every region. This leads to poor hygienic practices during menstruation and unsatisfactory sanitation. ${ }^{4}$

Recently, there has been an increase in health awareness campaigns in schools or colleges and initiatives taken by the government to augment the mass awareness, destigmatize the concept of menstruation, and improve 
the overall life of women in Pakistan. ${ }^{5}$ However, we still face extreme lack of knowledge, poor perception of menstruation, and detrimental practices among Pakistani population.

Menstrual hygiene management (MHM) is the most essential aspect of how a woman, hygienically manages her periods without compromising on the quality of her life. MHM is a rarely focused upon topic in the rural/slum areas of Pakistan. ${ }^{6}$ Most women lack awareness regarding healthy practices that are necessary to maintain good hygiene during menstruation. Not only do women lack awareness regarding menstruation, most women even lack the basic anatomical and physiological knowledge behind menstruation., ${ }^{7,8}$

In Pakistan and other developing countries, menstruation is highly stigmatized. This is more common in low socioeconomic squatter settlements of Karachi, Pakistan like Bizerta Lines where this study was conducted. ${ }^{9}$ The topic of menstruation is surrounded by deeply unsettling taboos and myths that had descended from our ancestors. In our society, many unsettling beliefs about menstruation are prevalent that suggest that menstruating women are impure, or that menstruation is something to be ashamed of. ${ }^{10}$

A thorough review of literature indicates that the traditional norms and misbeliefs accompanied by poor socio-economic conditions plays a pivotal role in barricading the adequate observation of hygienic practices among menstruating women in the region. ${ }^{11}$

One study from India reported that, menstruating women were restricted from participating in everyday activities like cooking and serving food. ${ }^{12}$ Similarly, in certain parts of India and Nepal, women aren't allowed to live in the residence with other family members, instead they stay in a separate section of the house. ${ }^{9}$

These cultural traditions prevent girls and women to perform daily activities and greatly impact the quality of their lives. Thus, the objective of this study was to determine the level of awareness and current menstrual hygiene practices among women of Bizerta Lines, Karachi, Pakistan.

\section{METHODS}

A cross-sectional observational study was undertaken at Bizerta Lines, Karachi, Pakistan between January 2019 and June 2019. A total of 338 women participated in the study. A non-probability, convenience sampling technique was applied.

\section{Inclusion criteria}

All menstruating women residing in Bizerta Lines Community and willing to be interviewed were included in the study.

\section{Exclusion criteria}

All women who were amenorrhoeic, pregnant, menopausal or had a history of birth control use were excluded from this study.

Ethical approval was obtained from the institutional review board (IRB) of Jinnah Sindh Medical University. After informed consent was obtained, data was collected by trained researchers. A thorough assessment of degree of awareness and current practices pertaining to menstrual hygiene management was done through detailed pro-forma which was previously translated in Urdu. The study tool collected the participant's knowledge, awareness, and misconceptions about menstruation. The factors affecting the quality of life during menstruation of women living in poor socioeconomic conditions were also observed. Statistical Package for Social Sciences (SPSS v.23) was used to organize, assess, and analyze the collected data. The resulting data was then reported in forms of charts, tables, and graphs.

\section{RESULTS}

A total of 338 women participated in the study. The mean age of the participants was $24.56 \pm 9.6$ years. $48.8 \%(165)$ of the participants were unmarried while $50.6 \%$ (171) participants were married. Only about $10.7 \%$ (36) of the participants had no formal education. Exactly $22.8 \%$ (77) of the women in the study were employed while, $77.2 \%$ (261) of the participants were financially dependent upon their family members (Table 1).

Table 1: Demographic characteristics of the participants $(n=338)$.

\begin{tabular}{|ll|}
\hline Demographic characteristics \\
\hline Age \\
\hline Mode & 15 years \\
\hline Minimum & 11 years \\
\hline Maximum & 55 years \\
\hline Marital status & \\
\hline Unmarried & $48.8 \%(165)$ \\
\hline Married & $50.6 \%(171)$ \\
\hline Widowed & $0.6 \%(2)$ \\
\hline Education level of participants & \\
\hline Uneducated & $10.7 \%(36)$ \\
\hline Primary (up to $5^{\text {th }}$ grade) & $21 \%(71)$ \\
\hline Secondary (up to 10 & grade) \\
\hline Higher secondary or equivalent & $47.3 \%(160)$ \\
\hline Bachelor's degree or equivalent & $15.1 \%(51)$ \\
\hline Master's degree or equivalent & $4.4 \%(15)$ \\
\hline Employment status & $1.5 \%(5)$ \\
\hline Employed & $22.8 \%(77)$ \\
\hline Unemployed & $77.2 \%(261)$ \\
\hline
\end{tabular}

Among the participants, $47.3 \%$ (160) reported to have experienced menarche at the age of 10-12 years, while $43.8 \%$ (148) had their first period at the age of 13-16 
years. 3.0\% (10) had their first period at the age of 8-10 years and $5.9 \%$ (20) had periods at the age of 17 years or more (Figure 1).

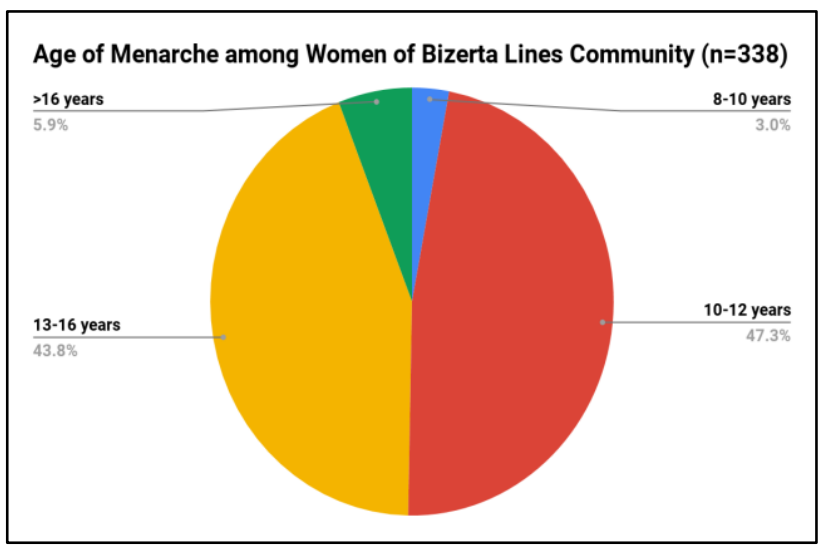

Figure 1: Age of menarche among participants $(\mathbf{n}=338)$.

Upon interviewing the participants about the basic physiology of puberty and menstruation, $82.5 \%$ (279) claimed they had no prior knowledge of menses before they experienced menarche. About $81.1 \%$ (274) reported that either their mother or sister imparted the knowledge about puberty and menstruation to them. Social media or awareness campaigns had very little contribution towards promoting the knowledge about the physiology of menstruation among women (Table 2).

Only $24.3 \%$ (82) of the participants knew that the source of menstrual blood was the uterus while $41.4 \%$ (140) of the women incorrectly claimed that the menstrual blood and urine were expelled from the same orifice. Out of 338 participants, $56.8 \%$ (192) remarked that even the elderly women menstruate. About $66.0 \%$ (223) of the women knew menstruation ceased during pregnancy. However, $66 \%$ (223) of the participants were aware that menstruation does not continue during the pregnancy (Table 2).

Table 2: Awareness about basic physiology of puberty and menstruation knowledge of menstruation before menarche.

\begin{tabular}{|c|c|}
\hline Item & $\mathbf{N}(\%)$ \\
\hline \multicolumn{2}{|c|}{ Knowledge of menstruation before menarche } \\
\hline Yes & $17.5(59)$ \\
\hline No & $82.5(279)$ \\
\hline \multicolumn{2}{|c|}{$\begin{array}{l}\text { Source of awareness about puberty and } \\
\text { menstruation }\end{array}$} \\
\hline Mother/elder sibling/female cousin & $81.1(274)$ \\
\hline School friend/senior & $7.7(26)$ \\
\hline Teacher/staff & $1.2(4)$ \\
\hline Social media/awareness campaigns & $2.7(9)$ \\
\hline Other source & $7.4(25)$ \\
\hline \multicolumn{2}{|l|}{ Source of menstrual bleeding } \\
\hline Vagina & $14.5(49)$ \\
\hline Urethra & $34.6(117)$ \\
\hline Stomach & $10.4(35)$ \\
\hline Uterus & $24.3(82)$ \\
\hline Other places from the abdomen & $9.8(33)$ \\
\hline I do not know & $6.5(22)$ \\
\hline \multicolumn{2}{|l|}{ Do older women menstruate? } \\
\hline Yes & $56.8(192)$ \\
\hline No & $19.2(65)$ \\
\hline I do not know & $24.0(81)$ \\
\hline \multicolumn{2}{|c|}{$\begin{array}{l}\text { Does the menstrual blood and urine come from the } \\
\text { same orifice? }\end{array}$} \\
\hline Yes & $41.4(140)$ \\
\hline No & $34.3(116)$ \\
\hline I do not know & $24.3(82)$ \\
\hline \multicolumn{2}{|c|}{ Do women menstruate during pregnancy? } \\
\hline Yes & $10.9(37)$ \\
\hline No & $66.0(223)$ \\
\hline I do not know & $23.1(78)$ \\
\hline
\end{tabular}

Table 3: Habits and practices of women during menstruation $(n=338)$.

\begin{tabular}{|ll|}
\hline Item & $\mathbf{N}(\%)$ \\
\hline I use sanitary napkins & $55.3(187)$ \\
\hline I use both sanitary napkins and new cloth & $2.4(8)$ \\
\hline I use both sanitary napkins and old cloth & $2.9(10)$ \\
\hline Only new cloth & $26.3(89)$ \\
\hline Only old cloth & $13.0(44)$ \\
\hline If you don't use sanitary napkins, state your reason? (n=151) & $18.5(28)$ \\
\hline Uncomfortable to use & $32.5(49)$ \\
\hline Expensive & $11.3(17)$ \\
\hline Not accessible & $23.2(35)$ \\
\hline Mothers encourages to use cloth & $11.3(17)$ \\
\hline No knowledge of sanitary napkins & $1.9(3)$ \\
\hline They cause cancer & $1.3(2)$ \\
\hline They cause infertility and birth defects & \\
\hline
\end{tabular}




\begin{tabular}{|c|c|}
\hline Item & $\mathbf{N}(\%)$ \\
\hline \multicolumn{2}{|c|}{ If you use "old cloth" (reuse it), how do you clean it? $(n=54)$} \\
\hline Water & $16.7(9)$ \\
\hline Water and soap & $70.3(38)$ \\
\hline Antiseptic & $12.9(7)$ \\
\hline \multicolumn{2}{|c|}{ If you use "old cloth" (reuse it), where do you dry it? $(\mathrm{n}=54)$} \\
\hline Inside with sunlight & $25.9(14)$ \\
\hline Inside without sunlight & $29.6(16)$ \\
\hline Outside with sunlight & $33.3(18)$ \\
\hline Outside without sunlight & $11.1(6)$ \\
\hline \multicolumn{2}{|c|}{ If you use "old cloth" (reuse it), where do you store it? $(n=54)$} \\
\hline Bathroom & $20.3(11)$ \\
\hline Cupboard & $57.4(31)$ \\
\hline Store room & $9.2(5)$ \\
\hline Suitcase & $1.8(1)$ \\
\hline Other & $11.1(6)$ \\
\hline \multicolumn{2}{|c|}{ How frequently do you change your absorbent? $(n=338)$} \\
\hline I don't change it all day. & $10.1(34)$ \\
\hline $1-3$ times a day & $65.1(220)$ \\
\hline 3-6 times a day & $18.6(63)$ \\
\hline$>6$ times a day & $6.2(21)$ \\
\hline \multicolumn{2}{|c|}{ How do you discard the absorbent after use? $(n=338)$} \\
\hline Bury it & $5.3(18)$ \\
\hline Burn it & $11.5(39)$ \\
\hline Throw it in the household trash & $68.0(230)$ \\
\hline Throw it separately & $15.1(51)$ \\
\hline \multicolumn{2}{|c|}{ How frequently do you clean your perineum during menses? $(n=338)$} \\
\hline$<2$ times a day & $22.2(75)$ \\
\hline$>2$ times a day & $77.8(263)$ \\
\hline \multicolumn{2}{|c|}{ What do you use to clean your perineum during menses? $(n=338)$} \\
\hline Water & $57.4(194)$ \\
\hline Water and soap & $29.0(98)$ \\
\hline Washcloth or sponge & $11.5(39)$ \\
\hline Old rags of cloth & $2.1(7)$ \\
\hline \multicolumn{2}{|c|}{ In which direction do you clean your perineum during menses? $(\mathrm{n}=338)$} \\
\hline Front to back & $53.0(179)$ \\
\hline Back to front & $13.9(47)$ \\
\hline No specific direction & $33.1(112)$ \\
\hline \multicolumn{2}{|c|}{ Do you dry your perineum after washing it during menses? $(n=338)$} \\
\hline Yes & $45.9(155)$ \\
\hline No & $54.1(183)$ \\
\hline \multicolumn{2}{|c|}{ Do you shower during menses? $(n=338)$} \\
\hline Yes & $62.4(211)$ \\
\hline No & $37.6(127)$ \\
\hline
\end{tabular}

Of the 338 women who participated in the study, $55.3 \%$ (187) claimed they used sanitary napkins while, $54.7 \%$ (151) women did not use sanitary napkins. Upon probing further, they explained their reasons for not using the sanitary napkins. For $32.5 \%$ (49) of the participants the pads were too expensive to use on a monthly basis, $23.2 \%$ (35) claimed their mothers encourage them to use cloth instead of sanitary pads, while $18.50 \%$ (28) felt uncomfortable using pads (Table 3 ).

\section{DISCUSSION}

Menstruation is a natural biological process which is experienced by all fertile women. However, the process of menstruation and its management can be challenging in developing countries like Pakistan where menstruation is viewed as something to be ashamed of. ${ }^{13}$ Menstruation in this region is encumbered with numerous misconceptions. This hinders the ability of the menstruating woman to lead a normal life and participate in everyday activities. ${ }^{8}$

In the present study, we documented the alarmingly high prevalence of inaccurate knowledge about reproductive anatomy and physiology behind menstruation as well as misconceptions and unhygienic practices associated with it. The data reported that more than three quarters i.e. $82.5 \%$ (279) of the participants had no information regarding menstruation prior to their first menstrual 
period. Mothers and sisters or female cousins were primary sources of information as reported by $81.1 \%$ (274) of the participants regarding menstruation. These findings were in accordance with previous studies from Nagpur and West Bengal. ${ }^{14,15}$ Teachers and social media or awareness campaigns had very limited to no role in terms of educating the girls regarding menstruation i.e. $1.2 \%$ (4) and $2.7 \%(9)$ respectively.

In our study, more than half the population $75.7 \%$ (256) assumed that the source of menstrual blood is urethra, vagina or other places from the abdomen while, only $24.3 \%$ (82) correctly cited uterus to be the source of menstrual blood. This finding is in line with the study reported by Thakre et al where he stated that $75 \%$ of the participants in his study were not aware of the source of the bleeding. ${ }^{14}$

About $41.4 \%$ (140) of women in the present study thought that the menstrual blood and urine comes from the same orifice. Seen as a global trend, women lack specific knowledge regarding their bodies, and they adhere to misconceptions regarding menstrual physiology which might be due to educational, socio-economic or religious barriers pertinent to that society. ${ }^{14-17}$ A study exploring the attitudes and knowledge pertaining to menstruation among students in Urmia, North West of Iran reported that majority of the girls had a negative attitude and lack of knowledge about menstruation which significantly affected the quality of their lives $(\mathrm{p}=0.05) .{ }^{16}$

Our study however, found that $66.0 \%$ (223) participants knew that pregnant women do not menstruate. However, this can be explained by the fact that $50.6 \%$ of the participants were married. These women may have experienced pregnancy themselves. One of the most important indicators of pregnancy is amenorrhea. ${ }^{18}$

In the present study, $55.3 \%$ (187) of the participants used sanitary napkins while, $54.7 \%$ (151) women used a combination of sanitary napkins and cloth or cloth alone. About $32.5 \%$ (49) of the participants in the study claimed that they could not afford sanitary pads, so they reverted to a more traditional and affordable method to manage their periods i.e. reusable pieces of cloth. Of them, $13.0 \%$ (44) had the practice of reusing the piece of cloth or rags. A study from Egypt supported the findings of the present study where $66.8 \%$ of the participants used sanitary pads, while $15.9 \%$ and $12 \%$ used recycled pieces of cloth or old rags for one-time use, respectively. ${ }^{19}$ This is one of the most vital menstrual hygiene problems faced by women living in low socioeconomic areas like Bizerta Lines, Karachi. The low accessibility and nonaffordability of the sanitary pads increases the risk of absenteeism from school or work and promotes urinary tract infections among women. ${ }^{20}$

In contrast to our findings, past studies conducted in the same geographical regions, it was reported that the majority of the women, especially those belonging to poor socioeconomic areas, were using old cloth as absorbent during menstruation and then reusing it after washing and drying. ${ }^{21-23}$ In one of the studies, it was reported that women dried their washed menstrual clothes away from sunlight in damp, hidden places so it was not visible to men in the house. This promotes unsanitary conditions which eventually leads to urinary tract infections, more severe pelvic infections and if untreated secondary infertility. ${ }^{22}$ Another striking finding of the present study was that $37.6 \%$ (127) of the participants avoid taking showers during their periods or menses. This finding can be attributed to the misconceptions and stigma attached to the topic of menstruation leading to lack of knowledge and state of unawareness among the women and young girls. ${ }^{24}$

Menstruation is a highly stigmatized topic in our society, and it is hardly discussed on a community level which hinders the progress in improving menstrual hygiene management, knowledge, and awareness among women in Pakistan. Strong evidence suggests that targeted interventions lead to better menstrual hygiene practices due to accurate menstrual knowledge and awareness of hygiene. $^{25}$

We did however face certain limitations when conducting this study. Firstly, the study population was confined to one particular locality which belonged to low and middle socioeconomic backgrounds due to which the results cannot be generalized for mass communities in Pakistan and can only be restricted for communities with similar demographic profiles. Secondly, many women were at first reluctant to participate in this study just as we had expected. To deal with this problem, our team of researchers were trained by a professional psychiatrist prior to initiating the study. The participants were explained the importance of this research and how they would be contributing significantly in raising awareness about menstruation among women in their community. While obtaining the consent from the participants we ensured that their absolute privacy and anonymity would be maintained.

\section{CONCLUSION}

Poor awareness, knowledge, and inadequate menstrual hygiene practices in developing countries like ours is a significant problem we face today. Community-based health awareness programs, availability and accessibility to affordable sanitary napkins, water supply, proper method of disposal, are some of the ways we can promote menstrual hygiene.

\section{Recommendations}

Further research should focus on the efficacy of community-based interventions where young girls and women are educated and guided about their sexual and reproductive health in a society-approved way. 


\section{ACKNOWLEDGMENTS}

We would like to thank Dr. Moiz Ahmed, the President of Student Council (tenure 2018-2019), Jinnah Sindh Medical University and his dedicated team for facilitating the research project.

\section{Funding: No funding sources}

Conflict of interest: None declared

Ethical approval: The study was approved by the Institutional Ethics Committee number JSMU/IRB/2020/316

\section{REFERENCES}

1. Salamonsen LA, Evans J. (2018). Menstruation and endometrial repair. In: Skinner MK, ed. Encyclopedia of Reproduction. 2nd ed. Academic Press; 2018:320-325.

2. World population 2020. Population clock live. Countrymeters.info. 2020. Available from: https://countrymeters.info/en/World. Accessed on 1 January 2020.

3. Menstrual cycle tool. womenshealth.gov. 2020. Available from: https://www.womenshealth.gov/ menstrual-cycle/your-menstrual-cycle\#3. Accessed on 1 January 2020.

4. Zaidi SH, Sivakami A, Ramasamy DJ. Menstrual hygiene and sanitation practices among adolescent school going girls: a study from a South Indian town. Int J Community Med Public Health. 2017;2(2):18994.

5. Mumtaz Z, Sivananthajothy P, Bhatti A, Sommer M. "How can we leave the traditions of our Baab Daada" socio-cultural structures and values driving menstrual hygiene management challenges in schools in Pakistan. J Adolesc. 2019;76:152-61.

6. Ali TS, Rizvi SN. Menstrual knowledge and practices of female adolescents in urban Karachi, Pakistan. J Adolesc. 2010;33(4):531-41.

7. Hennink M, Rana I, Iqbal R. Knowledge of personal and sexual development amongst young people in Pakistan. Culture Health Sexuality. 2005;7(4):31932.

8. Rizvi N, Ali TS. Misconceptions and mismanagement of menstruation among adolescent girls who do not attend School in Pakistan. J Asian Midwives. 2016;3(1):46-62.

9. Bhartiya A. Menstruation, religion and society. Int $\mathbf{J}$ Soc Sci Human. 2013;3(6):523.

10. Ali TS, Azam Ali P, Waheed H, Memon AA. Understanding of puberty and related health problems among female adolescents in Karachi, Pakistan. Journal of Pakistan medical association. 2006;56(2):68.
11. Mutunda AN. Factors impacting on the menstrual hygiene among school going adolescent girls in Mongu district, Zambia. School of Public Health. University of the Western Cape. 2013 May 30:1-81. Available from: https://akros.com/downloads/ papers/mutunda-study.pdf.

12. Bharadwaj S, Patkar A. Menstrual hygiene and management in developing countries: Taking stock. Junction Soc. 2004;3(6).

13. Burrows A, Johnson S. Girls' experiences of menarche and menstruation. J Reprod Infant Psychol. 2005;23(3):235-49.

14. Thakre SB, Thakre SS, Reddy M, Rathi N, Pathak K, Ughade S. Menstrual hygiene: knowledge and practice among adolescent school girls of Saoner, Nagpur district. J Clin Diagn Res. 2011;5(5):102733.

15. Sudeshna R, Aparajita D. Determinants of menstrual hygiene among adolescent girls: a multivariate analysis. Nat J Community Med. 2012;3(2):294-301.

16. Rabiepour S, Barjasteh S, Valizadeh R. Study of menstrual attitudes and knowledge among postmenarcheal students, in Urmia, North West of Iran. Int J Pediatr. 2017;5(5):4991-5001.

17. Patle R, Kubde S. Comparative study on menstrual hygiene in rural and urban adolescent. Int J Med Sci Public Health. 2014;3(2):129-33.

18. Klein DA, Paradise SL, Reeder RM. Amenorrhea: a systematic approach to diagnosis and management. Am Fam Phys. 2019;100(1):39-48.

19. El-Gilany AH, Badawi K, El-Fedawy S. Menstrual hygiene among adolescent schoolgirls in Mansoura, Egypt. Reprod Health Matters. 2005;13(26):147-52.

20. Garg R, Goyal S, Gupta S. India moves towards menstrual hygiene: subsidized sanitary napkins for rural adolescent girls- issues and challenges. Matern Child Health J. 2012;16(4):767-74.

21. Drakshayani KD, Venkata PR. A study on menstrual hygiene among rural adolescent girls. Indian J Med Sci. 1994;48(6):139-43.

22. Ali TS, Sami N, Khuwaja AK. Are unhygienic practices during the menstrual, partum and postpartum periods risk factors for secondary infertility? J Health Popul Nutr. 2007;25(2):189.

23. Nepal W. Is menstrual hygiene and management an issue for adolescent school girls. A comparative study of four schools in different settings of Nepal. 2009.

24. Johnston-Robledo I, Chrisler JC. The menstrual mark: Menstruation as social stigma. Sex Roles. 2013;68(1-2):9-18.

25. Kuhlmann AS, Henry K, Wall LL. Menstrual hygiene management in resource-poor countries. Obstetr Gynecol Survey. 2017;72(6):356.

Cite this article as: Usman G, Abbas K, Arshad R, Muneer A, Syed HS, Iqbal A, et al. Knowledge and practice of menstrual hygiene management among women living in a low-income neighbourhood, Karachi, Pakistan. Int J Reprod Contracept Obstet Gynecol 2020;9:3953-8. 